\title{
JOHN RAWLS: RA DE LA FILOSOFÍA POLÍTICA
}

\author{
Ángela Patricia Rincón Murcia* \\ Universidad Santo Tomás
}

Primitivamente, los gérmenes de todas las cosas reposaban en el seno de Nun, el caos, que contenía también, dentro de una flor de loto cerrada, al dios sol (Tum). Cansado de su inmovilidad, este dios se alzó un día sobre el caos y surgió, radiante, convertido en Ra. De él nació la primera pareja divina, y de su generación surgieron los grandes dioses Osiris, Isis, Set y Neftis.

\section{Problema sin resolver acerca de la conformación justa y moral del Estado}

Rawls trabaja en la línea de la filosofía política, buscando encontrar una teoría de la justicia social por medio de la repartición equitativa de derechos y deberes, de manera que no exista desigualdad en ninguna de las partes, ni siquiera en una pequeña minoría. Es decir, el ideal de justicia que busca Rawls no se dirige a proteger a las mayorías, sino a defender las libertades y diferencias propias de todos y cada uno de los individuos que conforman el Estado.

El interrogante que Rawls se plantea desde el inicio de su teoría es: ¿¿De qué se ocupa la filosofía política? A ello responde que esta disciplina no debe limitarse a reflejar la superficie de los diferentes enfoques ideológicos, sino que debe indagar en el fondo de sus debates y así reflexionar sobre su coherencia. De tal manera, su primer objetivo fue hacer una teoría coherente, la cual se basa en la idea de justicia. Por ello Rawls, quien se presentó varias veces como heredero de Kant, al iniciar su libro Teoría de la justicia ${ }^{1}$, nos expone que su objetivo radica en crear una teoría contractual de la justicia, tratando como nos explica Oscar Mejía Quintana en su libro Justicia y democracia consensualde "kantianizar a Hobbes, Locke y Rousseau y viceversa para lograr un contrato social moralmente fundamentado" 2 . Es decir, Rawls intenta superar las inconsistencias de las teorías contractuales expuestas antes de él, para

\footnotetext{
Estudiante de octavo semestre de la Facultad de Filosofía de la Universidad Santo Tomás, Bogotá.

RAWLS, John. Teoría de la justicia. Prefacio. México: Fondo de Cultura Económica, 1979.

2 MEJÍA QUINTANA, Oscar. Justicia y democracia consensual: la teoría neocontractualista de John Rawls. Bogotá: Siglo del Hombre Editores / Uniandes, 1997, p. 40.
} 
lograr elevar a un nivel más alto de abstracción la visión que hasta el momento se había tenido del contrato social. De esta manera, salva la idea del contrato social de Hobbes por su proceso de formación, es decir, en cuanto se lleva a cabo por medio de un compromiso de todos los hombres; pero la abandona por el objetivo que ésta persigue, esto es, que los hombres renuncien a sus derechos naturales para transferirlos a un tercero. En este tipo de gobierno vemos a los hombres sumidos en una minoría de edad, ajenos al derecho de una libertad individual que es eliminada, en cuanto pasa a ser parte del inmenso globo en que confluyen todas las libertades individuales. Dicho globo lo lleva en sus manos una especie de tutor encargado de brindar un supuesto orden al Estado.

De Rousseau, toma la idea de contrato, pero le aporta una fundamentación moral, tratando de evitar la arbitrariedad que podrían adoptar las mayorías si, justificadas en la colectividad, decidiesen tomar un camino dictatorial, violando así los derechos individuales. Es en este sentido que Rawls sigue a Locke, pues éste hace una defensa prioritaria de las libertades individuales que poseen valor independientemente de las mayorías que se presenten en el Estado. Ahora bien, el problema en la posición de Locke surge en el momento en que reduce dichas libertades a la posesión de una propiedad. Es decir, siguiendo su concepción, el individuo tiene derecho a su libertad en cuanto posee una propiedad privada, de manera tal que entre más propiedades tenga el individuo, más derechos ha de tener en el Estado. Como contrapunteo a tal posición, Rawls defiende las libertades individuales a partir del principio de diferencia, que consiste en que los menos aventajados han de recibir más privilegios, de manera que las ventajas no sean monopolizadas por un grupo, en tanto que los desaventajados pierden cada vez más. Por último, de Kant adopta la fundamentación moral que este propone para darle paso al Estado civil, pero rechaza su monologismo en la medida en que imposibilita llevar a cabo tal Estado ${ }^{3}$.

En realidad, la verdadera conformación de un Estado fundamentado en la justicia ha de estar dirigida al encuentro intersubjetivo de los individuos, en el que, como afirma Karl Otto Apel dentro de su teoría discursiva de la democracia, "todos tienen derecho a participar”4. Por ello, una máxima universal creada por un sujeto monológico resulta inaplicable para la conformación de una sociedad, ya que las leyes o normas que rijan al Estado donde todos interactuamos han de ser organizadas a partir de un consenso; es decir, deben dar cabida a la intersubjetividad dialógica que nos niega el sujeto trascendental de Kant, que incurre en la falacia de fundamentar la moral del Estado en la razón individual, sin dar paso al proceso comunicativo que nos permite exponer las posiciones de cada uno de los participantes para lograr un consenso legítimo que aporte bienestar a todos los individuos. Ahora bien, al hablar de todos los individuos, nos vemos obligados a abandonar la teoría apeliana, en tanto que busca absolutizar a la mayoría, cediéndole el derecho de negar la existencia de las libertades individuales. Vemos que Apel logra dar un paso más adelante que Kant para

3 Ibídem.

4 APEL, Karl Otto. Teoría de la verdad y ética del discurso. Barcelona: Paidós, 1991. Como fuente de crítica para la teoría apeliana he tomado a: HERNÁNDEZ PACHECO, Javier. Los límites de la razón: estudios de filosofía alemana contemporánea. Madrid: Tecnos, 1992. 
aportarle una fundamentación justa al Estado, es decir, logra superar al sujeto retraído en un monologismo pensante para trascender a un diálogo de tales razonamientos o, dicho de otra manera, eleva al sujeto trascendental hacia un consenso dialógico de la mayoría. Sin embargo, nos deja a mitad de camino, en cuanto que a partir de este diálogo llega a fundamentar la moral de las leyes en la decisión de la mayoría, sin atender a lo arbitrarias e injustas que éstas puedan ser al ir en contra de los derechos de los pequeños grupos que se encuentran por fuera de ellas. De esta manera, Apel relega el carácter de verdad de los argumentos del sujeto individual a la decisión de la mayoría, y si tal vez yo, como sujeto individual, expreso mi diferencia al no estar de acuerdo con esa mayoría, seré tildado de loco, y mi locura encontrará fin, si y sólo si acepto la decisión de dicha mayoría como verdad absoluta capacitada para eliminar mi derecho a la diferencia. En este sentido, vemos que si bien la fundamentación moral que propone Kant no logra dar paso al diálogo, haciendo nulo el carácter de justicia que pueda tener el contrato, pues sólo tiene en cuenta los razonamientos del yo pensante dejando de lado la interacción con los otros individuos, la propuesta discursiva de Apel en realidad deja el problema sin resolver, pues a pesar del diálogo propuesto, el carácter de justicia del contrato continuaría siendo nulo, ya que aunque habría un mayor número (ya no uno sino varios) de personas implicadas en la fundamentación de la justicia (pasamos del monologismo a la interacción dialógica), aún se está dejando por fuera a algunos agentes (las minorías), que, al igual que todos los individuos, tienen derecho a que sus libertades y sus diferencias sean respetadas, pues en la democracia comunitaria de Apel, si el individuo no logra confluir en el espíritu absoluto, en el que debe dejarse absorber, deberá ser llevado a un manicomio.

\section{Surgimiento de Rawls (Ra). Superación de las anteriores doctrinas}

Por todo lo anteriormente expuesto, nos percatamos de la imposibilidad de las diferentes teorías para hallar un fundamento justo y por ende moral para la conformación del Estado, si por moral entendemos el respeto a las libertades individuales, a la vez que la creación de un Estado basado en la igualdad. Es por ello que se hace necesario acudir a Rawls, con quien, al trabajar el siguiente interrogante, podemos trascender a una sociedad cuyo fundamento moral ha de basarse en el respeto a las diferencias de todos y cada uno de los individuos, que en su totalidad conformarían el legítimo Estado civil:

¿Cómo es posible que exista por tiempo prolongado una sociedad estable y justa de ciudadanos libres e iguales profundamente divididos por doctrinas razonables, aunque incompatibles, de índole religiosa, filosófica y moral?

Rawls se pregunta cómo es posible crear una sociedad justa y estable, de manera que, a pesar de que los ciudadanos posean diferentes ideologías y concepciones religiosas, morales, etc., exista una garantía de libertad e igualdad de oportunidades para todos. En este sentido, Rawls aboga por un pluralismo razonable, que se fundamente en el respeto por la opinión y las creencias de cada uno de los miembros de la sociedad, las cuales no han de ser un obstáculo para la constitución del Estado civil, sino que por el contrario, toda sociedad bien organizada ha de tener como fundamento el respeto a tales diferencias. Así, debido a que cada individuo tiene una concepción diferente de "vida buena”, es mejor buscar la idea de una "vida justa", que pueda ser aceptada por todos. Es por ello que el concepto de justicia adoptado en la teoría 
rawlsiana no se encuentra de ninguna manera restringido, es decir, lo justo no ha de tener excepciones de ningún tipo en su administración, no tendrá más o menos favorecidos, sino que, por el contrario, la justicia como equidad ha de ser el fundamento de toda sociedad bien ordenada.

De esta manera, la justicia debe poseer una connotación concreta e individualizable, es decir, radica en proteger la libertad de cada sujeto, de manera que dicha libertad jamás se encuentre en riesgo de ser violada so pretexto de proteger el bienestar de la mayoría. Dicha idea de justicia ha de ser adoptada de una manera radical, de forma tal que una injusticia sea aceptable si y sólo si sirve para evitar una injusticia mayor.

\subsection{Principios de justicia}

Para fundamentar la idea de justicia en el conjunto de la sociedad se hace necesario crear los principios de justicia social como medios para la distribución adecuada de los derechos y deberes que fundamentan la cooperación social, de manera que logren superar el conflicto de intereses que generalmente se presenta en la sociedad. Dichos principios que fundamentan la teoría de la justicia de Rawls son los siguientes:

1. Principio de igualdad: cada persona ha de tener un derecho igual al más amplio sistema total de las libertades básicas, compatible con un sistema similar de libertad para todos -igual libertad. Estas libertades básicas se refieren a: "la libertad de pensamiento y libertad de conciencia; las libertades políticas y la libertad de asociación; así como las libertades que especifican la libertad y la integridad de la persona; y, finalmente, los derechos y libertades que protegen las reglas de la ley"5.

2. Principio de las justas diferencias: a) las desigualdades económicas y sociales han de ser estructuradas de manera que sean para mayor beneficio de los menos aventajados, de acuerdo con un principio de ahorro justo - principio de diferencia-, y b) los cargos y las funciones deben ser asequibles a todos, bajo condiciones de justa igualdad de oportunidades — principio de la justa igualdad de oportunidades-. De tal manera, la injusticia para Rawls consiste en las desigualdades que no benefician a todos.

En este ámbito, Rawls nos expone la idea de un orden lexicográfico consecutivo que jerarquiza el sistema de cumplimiento de los principios, de manera que ningún principio pueda llevarse a cabo sin la previa consecución de los primeros. Dentro de dicha jerarquía se encuentra situado en primer lugar el principio de igual libertad, de manera que el principio de las desigualdades queda subordinado a él. Según Rawls, este orden lexicográfico nos ha de servir como criterio para solucionar las desavenencias que surjan dentro de la sociedad. Citando a Rawls, "esto quiere decir realmente que la estructura básica de la sociedad habrá de disponer las desigualdades de riqueza y de autoridad de modo que sean consistentes con las libertades iguales exigidas por el principio anterior” ${ }^{\circ}$.

Ahora bien, estos principios de la justicia surgen de la posición originaria, que consiste en el encuentro de los individuos (todos ellos en igualdad de condiciones) que desean formar la comunidad, los cuales de-

RAWLS, John. Liberalismo político. México: Fondo de Cultura Económica, 1995, p. 272.

6 RAWLS, John. Teoría de la justicia. Op. Cit. 
ben situarse tras un velo de ignorancia, que radica en tener en cuenta sólo el conocimiento que se tiene de la naturaleza, sin buscar datos de la experiencia que induzcan a pensar en algún tipo de privilegio; es decir, en el estado del velo de ignorancia, yo no puedo saber si en la sociedad que estamos conformando entre individuos racionales, voy a ser hombre o mujer, homosexual o heterosexual, blanco o negro, etc. Por tanto, no puedo pensar en ningún tipo de privilegio con respecto a los demás integrantes de tal sociedad. Una vez situados tras el velo de ignorancia, entra en juego el concepto de equilibrio reflexivo, que consiste en confrontar las implicaciones prácticas de los principios establecidos con nuestros juicios morales, de manera que, si hay conflicto, el principio debe ser rechazado, pues carece de coherencia. Es por ello que los individuos han de garantizar el carácter racional y moral de sus juicios de manera que ningún tipo de egoísmo intervenga en la imparcialidad de los mismos. Posteriormente, con estos supuestos realizados, los hombres han de escoger contractualmente los principios de justicia que han de regir su comunidad. De esta manera, queda garantizada la imparcialidad de los principios de la justicia. Y en contraposición con Apel, vemos que la conformación de los principios de justicia ha de contar con la participación de los individuos en igualdad de condiciones, situados tras un velo de ignorancia, aportando supuestos racionales y morales. De forma tal que al exponer sus argumentos no corren el peligro de ser tildados de locos y ser castigados por expresar sus diferencias como individuos que valen por sí mismos, independientemente de si hacen o no parte de la mayoría con la misma ideología. El giro que en este sentido toma la posición de Rawls con respecto a la tradición contractual, podemos entenderlo citando a Oscar Mejía, quien nos explica que esta posición original fundamentada en el velo de ignorancia es la que hace que la propuesta de Rawls supere las teorías contractualistas precedentes, en la medida en que logra "Primero, garantizar plenamente el procedimiento y la base consensual del contrato social; segundo, gracias... a las restricciones de información impuestas por el velo de ignorancia, imprimirle a la selección de los principios de la mayoría, la legitimidad moral que evite cualquier asomo de arbitrariedad"

En este sentido, entra en juego el concepto que tiene Rawls acerca de lo que es el ciudadano, a saber: es aquel que acepta los principios de justicia de la comunidad en la que está inscrito, reconociendo a los otros como agentes libres, racionales y morales. A su vez, el ciudadano es poseedor de una razón pública que caracteriza a la sociedad justa, pues consiste en la razón de los ciudadanos que comparten la calidad de ciudadanía en un sentido igualitario; el objetivo de dicha razón pública está dirigido al bien común, fundamentándose así en la idea de justicia.

\subsection{Desobediencia civil y grupos insurgentes en Colombia}

Ahora bien, si aún con todos los supuestos regulados para la conformación del Estado llegara a presentarse alguna inconsistencia en su administración, es decir, si se presentara alguna injusticia, ha de entrar en juego el derecho a la desobediencia civil, entendido por Rawls como un acto público, dirigido a promover un cambio en el sistema político, en vista de que los principios de justicia acordados para la conformación del Estado se están incumpliendo. Ahora bien, dicho acto ha de estar regido por principios racionales y conscientes, es decir, si bien va en contra de la ley, no por ello ha de ser violento.

\footnotetext{
7 MEJÍA QUINTANA, Oscar. Op. Cit., p. 47.
} 
En este ámbito entra en juego el tema de la Constitución colombiana, en relación con la aparición de grupos insurgentes, que parafraseando a Oscar Mejía, pone de manifiesto la crisis de legitimidad del ordenamiento de tal Constitución, en cuanto que no logró ampliar efectivamente el pacto de intereses representado por la constitución de $1886^{8}$. Ahora bien, aunque esta problemática se relaciona con el tema de la desobediencia civil, dicha relación se manifiesta de manera contrapuesta a la concepción rawlsiana de ésta, en la medida en que si bien la ideología que mueve a los grupos insurgentes supuestamente se dirige a la defensa de la soberanía popular, lo cual se relaciona con los argumentos de la filosofía política de Rawls, la desobediencia que dichos grupos expresan en sus acciones es de corte altamente violento, por lo cual no podemos aducirle una fundamentación rawlsiana a sus protestas.

Los grupos insurgentes de Colombia no representan un ejemplo de la concepción rawlsiana de desobediencia civil. Sus argumentos alegan el carácter de injusticia de la administración del gobierno (lo que llamaríamos en términos rawlsianos una denuncia ante el irrespeto de los principios de justicia que declaran la cooperación social y la libertad e igualdad de los ciudadanos). Ahora bien, ello lo hacen por medio de protestas violentas que degradan la dignidad de los individuos víctimas de sus ataques, personas que nada tienen que ver con sus protestas, pero que en justificación de una lucha con el Estado absoluto, confluyen en la masa hacia la cual dirigen sus ataques, eliminando por completo el derecho a la libertad propia que tiene el individuo. De manera que, mientras alegan la injusticia de la administración del Estado, se sostienen en la reitera- ción de actos como los múltiples secuestros, las famosas vacunas, no sólo a los grandes latifundistas del campo, sino incluso a pequeños propietarios campesinos que en el marco de una economía recesiva tratan de sostener a sus familias. En fin, atacan a todo un país que está conformado por personas que muchas veces ignoran la situación política, y sin embargo resultan siendo blanco de sus acciones. De esta manera, el lema de tales agrupaciones, que para muchos sectores de la ciudadanía podrían catalogarse como un grupo de bandidos, es salvar una ideología por medio del aniquilamiento del todo que se conforma por individuos que en su singularidad no poseen ningún valor.

Realmente, la desobediencia civil se justifica, como vemos con Rawls, en un acto racional que denuncie las inconsistencias de la administración del Estado. Si bien este acto va contra la ley, aboga por la soberanía popular y la libertad y derechos de los individuos, de manera que trata de superar dichas inconsistencias sin crear una incesable lista de injusticias para los individuos y para el Estado en general.

Para finalizar, he de acudir a la alegoría con la mitología egipcia, según la cual Ra surge del caos, cansado de su inmovilidad. Pues bien, Rawls se nos presenta a partir de un caos conformado por pensamientos, por supuesto valiosos, acerca del Estado y su conformación. Sin embargo, dichas teorías no habían logrado entablar la armonía de un Estado fundamentado moralmente, con respeto a la libertad e igualdad de los individuos. Ra (Rawls) emerge de la flor de loto cerrada, y en su descendencia nos trae a las divinidades llamadas posición original, equilibrio reflexivo, principios de justicia, desobediencia civil y libertades individuales.

8 MEJÍA QUINTANA, Oscar. La problemática iusfilosófica de la obediencia al derecho y la justificación constitucional de la desobediencia civil. Bogotá: Universidad Nacional, 2001. 